\title{
INGESTÃO PROTEICA E NECESSIDADES NUTRICIONAIS DE UNIVERSITÁRIOS VEGETARIANOS
}

\author{
PROTEIN INTAKE AND NUTRITIONAL NEEDS OF VEGETARIAN COLLEGE STUDENTS

\section{Elisiane Teixeira Rezende ${ }^{a^{*}}$, Samantha Estela Godinho ${ }^{b^{*}}$, Ana Cláudia Nogueira de Melo Souza ${ }^{\mathrm{c}^{*}}$, Lívia Garcia Ferreira $\mathrm{d}^{\mathrm{d}^{* *}}$} \\ aelisianerezende_2006@hotmail.com, bsamanthaestela@yahoo.com.br, canaclaudianms@gmail.com, diviagf@gmail.com \\ *Universidade de Itaúna - Itaúna (MG), Brasil \\ **Universidade Federal de Lavras - Lavras (MG), Brasil
}

Data de entrada do artigo: 24/06/2014

Data de aceite do artigo: 07/04/2015

\section{RESUMO}

Introdução: Atualmente a população vegetariana está aumentando significativamente, e com isso é recomendado que os profissionais da saúde tenham conhecimento necessário sobre o assunto e sobre os possíveis riscos e benefícios deste tipo de padrão alimentar. As fontes proteicas vegetais contêm proteínas em menor teor que as animais e apresentam aminoácidos limitantes. Consequentemente, vegetarianos necessitam consumir proteínas em maior quantidade. Objetivos: Avaliar a ingestáo proteica e compará-la a necessidades nutricionais de estudantes vegetarianos da Universidade de Itaúna (MG). Como objetivos secundários foram pesquisados o estado nutricional e os motivos e benefícios alegados para adoção da dieta vegetariana. Métodos: Foi realizada uma análise da quantidade de proteína ingerida por meio de um questionário de frequência alimentar quantitativo, contendo alimentos que possuem proteína. A concentração proteica dos alimentos foi avaliada utilizando a tabela de composição de alimentos (TACO) e a tabela de medidas caseiras e comparada às Dietary Reference Intakes [gestão dietética de referência] (DRI) conforme idade, sexo e peso. Resultados: Participaram do estudo 30 vegetarianos. Destes, 56,7\% foram classificados como semivegetarianos, $40,0 \%$, ovolactovegetarianos e $3,3 \%$, lactovegetarianos. Sobre a ingestão proteica, $76,7 \%$ dos participantes tiveram a ingestão adequada, sendo que deste total, $66,7 \%$ eram semivegetarianos e $88,2 \%$ ovolactovegetarianos. Quanto ao estado nutricional, $63,3 \%$ dos indivíduos foram classificados como eutróficos, $23,3 \%$, como baixo peso grau I e 13,3\%, como sobrepeso. Conclusão: A ingestão proteica foi atingida pela maioria dos indivíduos pesquisados. Houve maior índice de adequação em adeptos do semivegetarianismo. Entretanto, é importante que haja um acompanhamento nutricional específico para cada tipo de dieta vegetariana.

Palavras-chave: Dieta vegetariana; necessidades nutricionais; comportamento alimentar; necessidade proteica.

\section{ABSTRACT}

Introduction: Currently the vegetarian population is increasing significantly, and it is recommended that health professionals have the necessary knowledge of the subject and about possible risks and benefits of this type of diet. Vegetable protein sources contain lower protein content than animal and presents limiting amino acids. Therefore, vegetarians need to consume proteins in larger quantities. Objectives: To asses protein intake and compare it to nutritional needs of vegetarian college students of University of Itaúna $(\mathrm{MG})$. As secondary objective was research the nutritional status and the motives and claimed benefits for adopting a vegetarian diet. Methods: An analysis of protein intake through a quantitative questionnaire of food frequency containing food that have protein was performed. Protein concentration of the food was assessed using a food composition table (TACO) and the table of portion sizes and compared according to the Dietary Reference Intakes (DRI) as age, sex and weight. Results: The study included 30 vegetarians. Of these, $56.7 \%$ were classified as semi-vegetarians, $40.0 \%$ ovolactovegetarians and $3.3 \%$ lacto-vegetarians. On protein intake, $76.7 \%$ of participants had adequate intake, and of this total, $66.7 \%$ 
were semi-vegetarians and $88.2 \%$ ovolactovegetarians. Regarding nutritional status, $63.6 \%$ of subjects were classified as normal, $23.3 \%$ as undeweight grade I and $13.3 \%$ as overweight. Conclusion: Protein intake was reached by most of those surveyed. There was more appropriate level for semi-vegetarianism adherents. However, it is important to have a specific nutritional counseling for each type of vegetarian diet.

Keywords: Vegetarian diet; nutritional requirements; feeding behavior; protein needs.

\section{Introdução}

O número de vegetarianos está aumentando no Brasil e no mundo. Há vários indícios desse aumento no Brasil, como a maior oferta de produtos alimentícios de origem vegetal, aumento de publicações sobre o assunto, produção e comercialização de orgânicos e restaurantes adaptados para este padrão ${ }^{1}$. A adesão ao padrão alimentar vegetariano pode ocorrer por diferentes motivos, como religiáo, ética, saúde, ecologia e economia ${ }^{2}$.

Normalmente vegetarianos são aqueles que restringem todos os alimentos de origem animal. Dependendo do consumo dos derivados animais em sua dieta, o vegetariano recebe uma terminologia distinta. $\mathrm{O}$ vegano, ou vegetariano estrito, é aquele que não consome alimentos provenientes de animais. Os lactovegetarianos são os que consomem leite e seus derivados; os ovolactovegetarianos consomem leite, seus derivados e ovos. Além disso, vem surgindo um novo grupo denominado semivegetariano, que são aqueles que consomem carnes brancas e excluem as vermelhas ${ }^{3}$.

As dietas vegetarianas têm muitas vantagens sobre dietas onívoras, dentre elas os baixos níveis de gordura saturada, colesterol, proteína animal, níveis mais elevados de carboidratos complexos, fibras, magnésio, boro, folato, vitaminas $\mathrm{C}$ e $\mathrm{E}$, carotenoides e fitoquímicos. Contudo, as desvantagens podem ser a baixa ingestão de vitamina $\mathrm{B}_{12}$, vitamina $\mathrm{D}$, cálcio, ferro, zinco e riboflavina ${ }^{4}$

Uma das preocupaçóes dos profissionais da área da saúde a respeito da dieta vegetariana é a ingestão proteica, principalmente em relação aos aminoácidos essenciais, já que a proteína de origem animal é uma das melhores fontes desses aminoácidos ${ }^{5}$. O valor nutricional de uma proteína depende de sua composição em aminoácidos e de sua digestibilidade. Se uma proteína obtiver quantidade desproporcional de um ou mais aminoácidos, ela não será utilizada totalmente, sendo que a quantidade adequada para atender as recomendaçôes será maior do que para uma proteína que possua um padrão de aminoácidos balanceado e possua maior digestibilidade. As fontes proteicas vegetais contêm proteínas em menor teor do que as animais e apresentam aminoácidos limitantes; consequentemente, vegetarianos necessitam consumir proteínas em maior quantidade. Para vegetarianos estritos recomenda-se $1,0 \mathrm{~g}$ de proteína por kilo de peso corporal, comparada a $0,8 \mathrm{~g} / \mathrm{kg}$ de peso corporal recomendada para onívoros saudáveis ${ }^{6}$. Baseando-se na baixa digestibilidade das proteínas vegetais, alguns autores afirmam que a necessidade proteica de indivíduos veganos pode ser maior de 30\% a 35\% para crianças até dois anos de idade, de $20 \%$ a $30 \%$ para crianças de dois a seis anos de idade e de $15 \%$ a $20 \%$ para crianças maiores de seis anos de idade, em comparação com aquelas que não são vegetarianas ${ }^{7,3}$.

Entretanto, as pesquisas mostram que a disponibilidade de alimentos vegetais ingeridos durante todo o dia pode fornecer todos os aminoácidos essenciais e garantir adequada retenção de nitrogênio em adultos saudáveis, eliminando a suplementação de proteínas em uma mesma refeição 5 .

Sendo assim, é necessário que se faça uma correta distinção entre os diferentes padróes alimentares vegetarianos para a avaliaçáo do estado de saúde e nutrição dos praticantes destes tipos de alimentaçáo. Além disso, a avaliação da ingestão dietética quantitativa é essencial para se conhecer as inadequaçóes nutricionais e promover dietas balanceadas para prevenção e/ou tratamento das possíveis carências ${ }^{6}$. Diante disto, o objetivo principal deste estudo foi avaliar quantitativamente a ingestão proteica de estudantes da Universidade de Itaúna (MG). Como objetivos secundários, foram pesquisados o estado nutricional, os motivos e os benefícios alegados pelos universitários para adoção da dieta vegetariana.

\section{Métodos}

Trata-se de um estudo transversal realizado na Universidade de Itaúna, Minas Gerais. O estudo foi aprovado pelo Comitê de Ética em Pesquisa da referida universidade com protocolo de $\mathrm{n}^{\circ} 044 / 11$, e a coleta de dados foi realizada no período de março a abril de 2012. A pesquisa foi feita com estudantes universitários matriculados em todos os cursos da universidade.

A amostra foi constituída por alunos que se consideravam vegetarianos ou semivegetarianos e que tiveram interesse e espontânea vontade em participar da pesquisa, independentemente do sexo e idade dos indivíduos. Os alunos receberam esclarecimento prévio sobre a natureza da pesquisa e a adesão ao estudo foi realizada 
mediante assinatura do termo de consentimento livre e esclarecido.

Após a assinatura os alunos receberam uma ficha para classificação do tipo de vegetarianismo na qual se encaixava, de acordo com o Quadro 1.

Quadro 1: Classificação quanto aos tipos de vegetarianismo e suas características

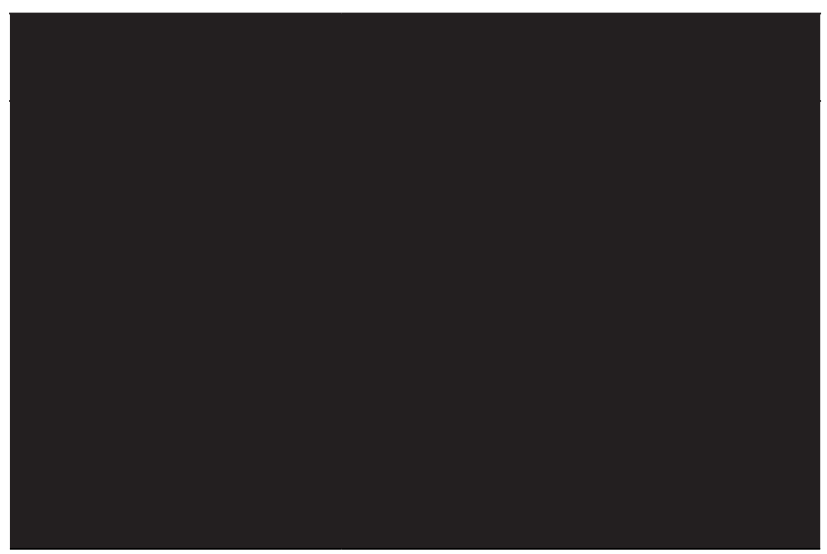

Fonte: Couceiro et al.; 2008

Nesta ficha também foram informados o sexo, o peso e a altura dos indivíduos para posterior cálculo do índice de massa corporal (IMC), na qual os indivíduos foram classificados de acordo com os critérios da Organização Mundial da Saúde ${ }^{8}$. Além disso, também foi pesquisado o motivo que levou o vegetariano a ter esse tipo de alimentação, há quanto tempo ele segue esse padrão alimentar e se possui algum benefício diante disso. Os alunos também receberam um questionário de frequência alimentar quantitativo, dividido em grupos de alimentos que contém proteína, como: massas, pães e cereais, leguminosas, leite e derivados, ovos e carnes. Os participantes deveriam indicar a frequência diária e a quantidade de consumo em medidas caseiras. Foram adicionados ao questionário desenhos referentes ao tamanho das medidas caseiras para minimizar os erros na quantificação do registro alimentar.

A partir destes dados, foi calculada a ingestão proteica diária obtida a partir da tabela de composiçáo de alimentos (TACO) $)^{9}$ e da tabela de medidas caseiras ${ }^{10}$.

Para verificar a adequaçáo da ingestáo proteica foi feita uma comparação com a recomendaçáo das Dietary Reference Intakes [gestáo dietética de referência] (DRI) ${ }^{11}$, mediante a idade, peso e sexo dos participantes.

O banco de dados foi feito em planilhas do Microsoft Excel e as análises estatísticas foram realizadas pelo Statistical Package of Social Science versão 16.0. A normalidade das variáveis quantitativas foi examinada pelo teste de Kolmogorov-Smirnov. As variáveis com distribuição normal foram apresentadas através da média e desvio padrão, e as variáveis com distribuição não normal através de mediana, mínimo e máximo. As variáveis categóricas foram apresentadas através da frequência em que ocorreram.

\section{Resultados}

A amostra do presente estudo consistiu em 30 alunos que se classificaram entre os tipos de vegetarianismo, sendo $63,3 \%(n=19)$ do sexo feminino e $36,7 \%$ $(\mathrm{n}=11)$ do sexo masculino, com idade média de $23 \pm$ 4,89 anos. Os cursos que tiveram maior porcentagem de vegetarianos foram direito, com $30 \%(n=9)$ de universitários, os cursos da área da saúde e os cursos de engenharia, ambos com $23,3 \%(n=7)$, o curso de administração, com 10,0\% ( $\mathrm{n}=3)$, e outros cursos, com $13,3 \%(n=4)$ dos estudantes.

De acordo com a classificação do Índice de Massa Corporal (IMC), 63,3\% ( $\mathrm{n}=19)$ foram classificados eutróficos, $23,3 \%(n=7)$, baixo peso grau I e 13,3\% ( $n=4)$, sobrepeso. $\mathrm{O}$ tempo médio em que os indivíduos adotaram o padrão alimentar vegetariano foi de 6 anos (1 mês a 26 anos). A Tabela 1 demonstra os motivos apresentados pelos universitários para terem se tornado vegetarianos e a Tabela 2 apresenta os benefícios da dieta vegetariana alegados por eles.

Tabela 1: Motivo para se tornar vegetariano, segundo os universitários do estudo

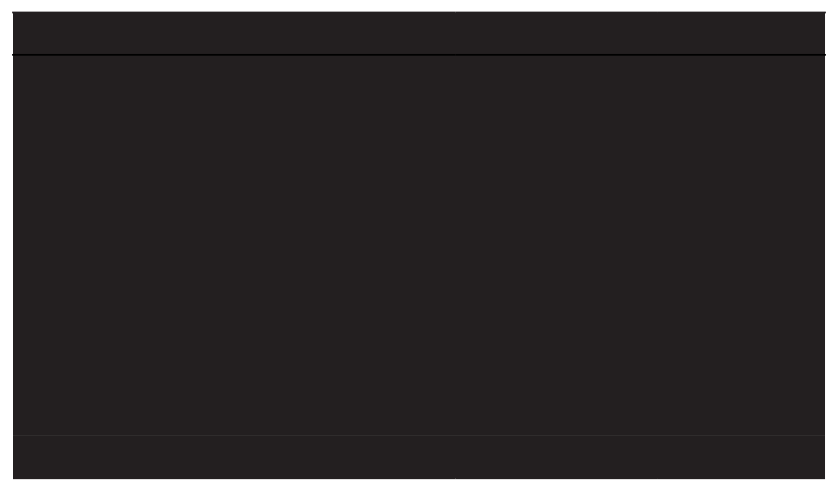

Tabela 2: Benefícios alegados com a dieta vegetariana, segundo os universitários do estudo

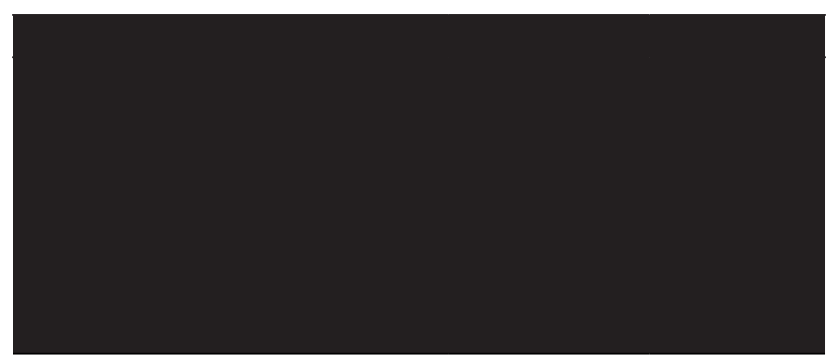


Dos 30 vegetarianos que preencheram o questionário, $56,7 \%(\mathrm{n}=17)$ se classificaram semivegetarianos, $40,0 \%(n=12)$, ovolactovegetarianos e $3,3 \% \quad(n=1)$, lactovegetarianos.

A média da ingestáo proteica foi de 70,4 $\mathrm{g}(16,0 \mathrm{~g}$ a $211,0 \mathrm{~g}$ ), sendo que foi separada quanto aos grupos de vegetarianismo, de acordo com a Tabela 3.

Tabela 3: Média e mediana da ingestão proteica de universitários vegetarianos conforme a classificação do vegetarianismo

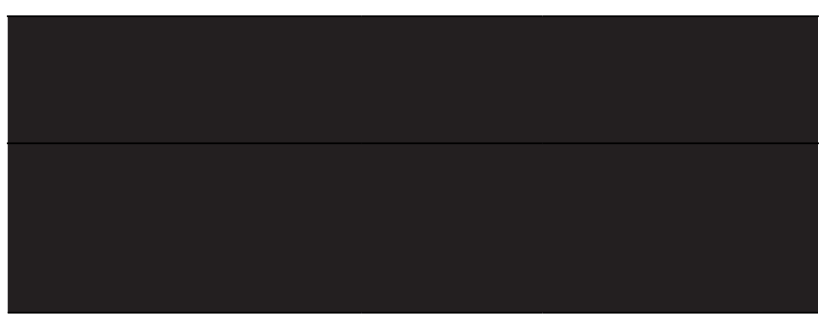

Quanto à adequação da dieta em relação à proteína ingerida, 76,7\% ( $\mathrm{n}=23)$ dos indivíduos, tiveram ingestáo proteica adequada. A Figura 1 apresenta a adequação de proteínas conforme a classificação dos tipos de vegetarianismo.

Figura 1: Adequação de proteínas por g/kg/dia ingeridas por universitários vegetarianos conforme a recomendação das Dietary References Intakes [gestão dietética de referência] (DRI). (DRIs, 2002)

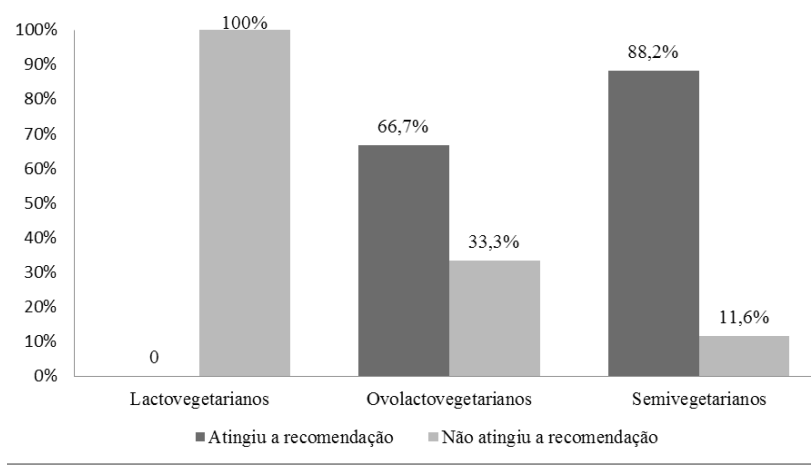

\section{Discussão}

Ainda há poucos estudos publicados sobre a quantificação da ingestão proteica de universitários vegetarianos, o que consequentemente constitui uma limitação à comparabilidade dos resultados apresentados. Entretanto, tal fato demonstra que este trabalho se torna um dos pioneiros no assunto.

A alimentaçấo vegetariana pode levar à perda de peso, à manutençâo do peso e à obesidade. Tudo isso vai depender da dieta, do estilo de vida e da composiçáo metabólica do indivíduo ${ }^{12}$. De acordo com Davey et al. ${ }^{13} \mathrm{em}$ estudo populacional comparando vegetarianos com onívoros, vegetarianos apresentaram IMC menor quando comparados a onívoros. Miranda et al. ${ }^{14}$ avaliaram o estado nutricional de vegetarianos de acordo com o IMC e constataram que $74 \%$ dos participantes eram eutróficos e $26 \%$ apresentavam sobrepeso ou obesidade. Já no presente estudo 63,3\% dos participantes foram classificados como eutróficos e $23,3 \%$ classificados como baixo peso. O percentual de sobrepeso encontrado foi de $13,3 \%$. De acordo com a Pesquisa de Orçamentos Familiares ${ }^{15}$, 32,9\% dos adultos jovens brasileiros (20 a 24 anos) apresentam sobrepeso e obesidade, dado superior ao do presente estudo e de outros com jovens vegetarianos ${ }^{14}$.

Dentre os motivos para adotar a dieta vegetariana, os mais citados pelos vegetarianos foram o fato de não gostarem de carnes, especificamente vermelhas, e a pena dos animais, ressaltando a forma como os animais são mortos para a obtenção do consumo. $\mathrm{O}$ bem estar do animal também é citado pelo Mintel International Group Limited ${ }^{16}$ como uma das razóes mais comuns para se adotar dietas vegetarianas. $\mathrm{O}$ grupo também cita como principais fatores as consideraçóes com saúde e preocupação com o meio ambiente. Apesar da preocupaçáo do meio ambiente ser comum entre os vegetarianos ${ }^{16}$, nenhum participante deste estudo citou esse fator como causa da adoção da dieta vegetariana. De acordo com Greif ${ }^{17}$, atualmente o meio ambiente é o que mais pesa na decisão de alimentar-se com a carne.

Quanto aos benefícios alegados das dietas vegetarianas, a população estudada relatou melhora na digestão, melhor condicionamento físico, saciedade, redução de colesterol, alimentação mais saudável e, por último, perda de peso. Conforme Sacks e Kass ${ }^{18}$, os vegetarianos consomem frutas e legumes em maior quantidade e ingerem menos quantidades de doces, fast food e salgadinhos em comparação com onívoros. Isso pode estar relacionado à preocupação de se obter uma alimentação mais saudável. No presente estudo a alimentação saudável foi um dos benefícios alegados por $10 \%$ dos estudantes universitários. As dietas vegetarianas são ricas em fibras que sofrem ação bacteriana no cólon e aumentam a síntese de nitrogênio, além da alta ingestão de fibras causar redução dos níveis séricos de colesterol, redução de risco e prevalência de doença cardiovascular, hipertensão arterial, diversos tipos de câncer e diabetes tipo $2^{12}$. A melhora do condicionamento físico foi alegada por $16,7 \%$ dos participantes como benefícios das dietas vegetarianas. No entanto, de acordo com Ferreira et al. ${ }^{19}$, não foram encontradas diferenças significativas na capacidade aeróbica e de força em indivíduos que seguiram diferentes dietas. 
No que se refere ao desempenho hipertrófico ou de força e potência muscular, os estudos ainda não são conclusivos.

Dados do Instituto de Opinião Pública e Estatística ${ }^{20}$ apresentam que 10\% dos homens e 9\% das mulheres brasileiras se declaram vegetarianos. No entanto, neste trabalho, observaram-se mais mulheres $63,3 \%$ (19) do que homens $36,7 \%$ (11), com a idade média de 23 anos. Essa diferença entre os sexos pode ser pela maior presença de mulheres em universidades, que segundo Leta $^{21}$, são maioria nos cursos de graduação e pós-graduação do país. Dados recentes dos alunos das universidades brasileiras apontam que em 2001 as mulheres representavam $56,3 \%$ do total de matriculados e $62,4 \%$ do total de concluintes dos cursos ${ }^{22}$.

Segundo Skemiené ${ }^{23}$, os alunos de medicina e nutrição serão os especialistas que irão orientar a população quanto ao estilo de vida e nutrição nos benefícios à saúde futuramente. Os alunos da área da saúde em geral se preocupam mais em ter uma alimentação saudável e por isso adotam dietas vegetarianas, para terem melhores hábitos alimentares. No presente estudo, entretanto, observa-se que a maioria dos universitários vegetarianos não são da área da saúde $(76,7 \%)$, talvez pelo fato dos demais cursos apresentarem mais alunos.

Este estudo buscou identificar se a população em estudo tinha alimentação balanceada capaz de fornecer a quantidade de proteína recomendada. Para a avaliação da ingestão proteica foi utilizado questionário de frequência alimentar constando alimentos que contém proteína em sua composição. Tal método é rápido na hora do preenchimento e minimiza os riscos de sub-relato da amostra $^{24}$. Outros métodos utilizados em estudos para avaliação da ingestão alimentar são recordatórios e registros alimentares, mas são questionados por vários autores, pois os indivíduos podem alterar os hábitos alimentares e a quantidade relatada dos alimentos ${ }^{25}$. Também se pode ressaltar que o objetivo da pesquisa não era estimar o valor calórico da alimentação dos alunos, mas a quantidade de proteína. Além disso, o público era de difícil acesso e o tempo para realização da pesquisa curto, sendo outro motivo para se utilizar o questionário de frequência alimentar.

Conforme resultados obtidos, $76,7 \%$ dos participantes atingiram a recomendação proteica necessária. Dados semelhantes foram encontrados em estudo realizado por Miranda et al. ${ }^{14}$, em que $82 \%$ dos vegetarianos atingiram as recomendaçóes de proteína. Quanto à ingestáo proteica analisada por tipo de dieta vegetariana, $88,2 \%$ dos semivegetarianos e $66,7 \%$ dos ovolactovegetarianos tiveram a ingestão proteica suficiente para atingir as recomendaçóes. Miranda et al. ${ }^{14}$, analisando a ingestão proteica de vegetarianos pelo mesmo método, constataram que $86 \%$ dos ovolactovegetarianos e $89 \%$ dos lactovegetarianos ingeriam quantidades adequadas de proteína. Em nosso estudo apenas um indivíduo se declarou lactovegetariano, tendo ingestão de proteína de apenas 30,0 g por dia, o que está bem abaixo das recomendaçóes. Os resultados demonstram que mesmo em ambiente acadêmico há necessidade de maiores esclarecimentos sobre as fontes de proteína e as composiçóes adequadas das mesmas. Muitos acadêmicos, ao preencherem o questionário de frequência alimentar, relataram não saberem que os cereais continham proteína (dados não apresentados). Segundo a Sociedade Vegetariana Brasileira ${ }^{26}$, os teores proteicos de alimentos vegetais são inferiores aos de proteínas de fontes animais. No entanto, os alimentos vegetais são capazes de suprir as necessidades do organismo utilizando alimentos fontes de proteínas como leguminosas e cereais. Além disso, os derivados de animais, como ovos e leite, também contribuem para fornecer aminoácidos essenciais na dieta sem carne. Como a proteína é facilmente obtida na alimentação diária, consequentemente a literatura científica relata que a alimentação de indivíduos vegetarianos não apresenta maiores riscos desde que náo restrinja a quantidade de energia ingerida ${ }^{26}$.

\section{Conclusão}

Embora a população estudada seja uma amostra pequena, devido às dificuldades em encontrar vegetarianos universitários, a ingestáo proteica foi atingida pelo maior percentual de indivíduos pesquisados. Houve maior índice de adequação em adeptos do semivegetarianismo, ou seja, aqueles que restringem somente carnes vermelhas.

Apesar do estudo não contemplar indivíduos estritos/veganos, a literatura demonstra que pode ser um pouco mais difícil para estes atingirem a recomendação de proteína. Entretanto, por meio de uma alimentação balanceada e orientada, é possível encontrar todos os aminoácidos essenciais para suprir a necessidade do organismo. Sendo assim, é importante que haja um acompanhamento nutricional específico para cada tipo de dieta vegetariana.

\section{Referências}

1. Nascimento IS. Vegetarianos do Brasil: Consumo x produção de carne. 2008. Monografia - Centro de Desenvolvimento Sustentável Universidade de Brasília (CDE-UnB), Brasília, 2008.

2. Souza AN, Araújo AP, Alvarenga D, Freitas L, Zamagno M. Alimentação vegetariana [monografia da internet]. UFJF, 
Juiz de Fora; 2010 [acesso em 15 jan 2012]. Disponível em: http://scholar.google.com.br/

3. Couceiro P, Slywitch E, Lenz F. Padrão alimentar da dieta vegetariana. Einstein 2008;6(3):365-73.

4. Angelis RC. A importância dos alimentos vegetais na proteção da saúde. $2^{\text {a }}$ ed. São Paulo: Atheneu; 2005.

5. Young VR, Pellett PL. Plant proteins in relation to human protein and aminoacid nutrition. Am J Clin Nutr. 1994;59:1203-1212.

6. Miranda N, Bortoli MC, Cozzolino SMF. Nutrientes e dietas vegetarianas. In: Cozzolino SMF. Biodisponibilidade de nutrientes. $3^{\mathrm{a}}$ ed. Barueri: Manole; 2009. p. 1107-1140.

7. Messina V, Mangels AR. Considerations in planning vegan diets: children. J Am Diet Assoc. 2001;101(6):661-9.

8. World Health Organization. Obesity: preventing and managing the global epidemic - report of a WHO consultation on obesity. Geneva: World Health Organization, 1997.

9. Unicamp. Tabela brasileira de composição de alimentos/ NEPA-Unicamp. Versão II. 2a ed. Campinas: NEPAUnicamp; 2006.

10. Pinheiro ABV, Lacerda EMA, Benzecry EH, Gomes MCS, Costa VM. Tabela para Avaliação de Consumo Alimentar em Medidas Caseiras; 2006.

11. Dietary reference intakes for energy, carbohydrate, fiber, fat, fatty acids, cholesterol, protein and amino acids. Institute of Medicine, Food and Nutrition Board: National Academic Press; 2005. p. 589-762.

12. Guia alimentar de dietas vegetarianas para adultos; 2012. [Acesso em: 15 de fev 20012]. Disponível em: www.svb.org. $\mathrm{br} /$ vegetarianismo/index.php

13. Davey GK, Spencer EA, Appleby PN, Allen NE, Knox $\mathrm{KH}$, Key TJ. EPIC-Oxford: lifestyle characteristics and nutrient intakes in a cohort of 33883 meat-eaters and 31546 non meat-eaters in the UK. Public Health Nutr. 2003;6(3):259-69.

14. Miranda DEGA, Gomes AR, Morais JÁ, Tonetti TC, Vassimon HS. Qualidade nutricional de dietas e estado nutricional de vegetarianos. Demetra. 2013;8(2):163-172

15. Brasil. Instituto Brasileiro de Geografia e Estatística. POF 2008-2009: desnutrição cai e peso das crianças brasileiras ultrapassa padrão internacional. 27 ago 2010 [acesso em: 1 jun 2012]. Disponível em: http://cod.ibge.gov.br/27ly0.

16. Mintel International Group Limited. Eating habits-US. July 2004. Chicago, IL: Mintel International Group Limited; 2004.

17. Greif S. Vegetarianismo e prevenção à poluição. [Acesso em: 10 de jan 2012]. Disponível em: http://www.svb.org. br/depmeioambiente/VegetarianismoePrevencaoaPoluicao. htm

18. Sacks FM, Kass EH. Baixa pressão arterial em vegetarianos: efeitos de alimentos específicos e nutrientes. Am J Clin Nutr. 1988;48:795-800.

19. Ferreira LG, Burini RC, Maia AF. Dietas vegetarianas e desempenho esportivo. Rev Nutr. 2006;19(4):469-477.

20. Instituto Brasileiro de Opinião Pública e Estatística. Mídia revela hábitos de saúde e de consumo da mulher brasileira [acesso em 17 maio 2012]. Disponível em: http:// www.ibope.com.br/calandraWeb/servlet/CalandraRedirect?temp $=5 \&$ proj=PortalIBOPE \&pub=T\&db=caldb\&com$\mathrm{p}=\mathrm{IBOPE}+\mathrm{M} \% \mathrm{ED}$ dia $\&$ docid $=092582 \mathrm{CC} 36 \mathrm{D} 2 \mathrm{FBFB}-$ $8325784800405 \mathrm{FB} 8$.

21. Leta J. As mulheres na ciência brasileira: crescimento, contrastes e um perfil de sucesso. Est Avanç. 2003;17(49):271-284.

22. INEP/MEC, Instituto Nacional de Estudos e Pesquisas Educacionais Anísio Teixeira. EDUDATABRASIL - Sistema de Estatísticas Educacionais [acesso em: 01 jun 2012]. Disponível em: http://www.edudatabrasil.inep.gov.br/

23. Škèmienė L, Ustinavičienė R, Piešinè L, Radišauskas R. Department of environmental and occupational medicine. Lithuania: Kaunas University of Medicine; 2007.; 43(2).

24. Scagliusi FB, Júnior AHL. Subnotificação da ingestão energética na avaliação do consumo alimentar. Rev Nutr. 2003;16(4):471-481.

25. Schoeller DA. How accurate is self-reported dietary energy intake? Nutr Rev. 1990;48:373-9.

26. Sociedade Vegetariana Brasileira [homepage na internet]. Tudo o que você precisa saber sobre alimentação vegetariana [acesso em: 28 maio 2012]. Disponível em: www. svb.org.br 